\title{
DFT Study of the Interaction between Chloroiron(III) Porphyrin and Poly(methyl Methacrylate) Macroradicals
}

\author{
Anna K. Friesen \\ Institute of Organic Chemistry, Ufa Scientific Centre of Russian Academy of Sciences, Ufa, 450054, Russia \\ E-mail:friesenak@rambler.ru
}

\begin{abstract}
The heats of possible reactions between the model poly(methyl methacrylate) radical (PMMA) and the molecule of iron chloroporphyrin (FeClP) were calculated by density functional theory methods. It was shown that the interaction of iron atom of FeClP and PMMA radical energetically is more favourable via the carbonyl group of the latter. The chlorine atom transfer reaction between PMMA radical and FeClP containing Fe atom in the spin state 3/2 is the most probable process among the studied reactions.
\end{abstract}

Keywords: Chloroiron(III) porphyrin, poly(methyl methacrylate) radical, controlled radical polymerization, density functional theory.

\section{Introduction}

Controlled radical polymerization (CRP), mediated by transition metal complexes, is the important advance in polymer chemistry. All the methods of CRP are based on the reducing of concentration of propagating radicals, that results in decrease the probability of irreversible bimolecular chain termination reactions. The transition-metal complexes, which contain the halogen atoms, can act as the regulators of the concentration of radicals by two possible ways: 1) the reversible formation of metal-carbon bond, in which the complex acts as a spin trap; 2) the reversible transfer of a halogen atom to the active radical, thereby transforming it into halogen-terminated dormant chain. In the first case, the polymerization process is named "organometallic radical polymerization" (OMRP $\left.{ }^{[1]}\right)$, and in the second case it is named "reverse atom transfer radical polymerization" (reverse ATRP ${ }^{[2]}$ ).

It is known that the metalloporphyrins may be used for CRP. ${ }^{[3]}$ It was shown previously ${ }^{[4]}$ that the iron complex of 5,10,15,20-tetrakis(3,5-di-tert-butylphenyl)porphine with axial chlorine (FeClP) influences the rate of substantially initiated radical polymerization of methyl methacrylate (MMA), the molecular weight and the microstructure of obtained polymer. It is probable, that FeClP interacts with poly(MMA) propagating radicals and decreases their concentration. It is necessary to reveal the possible mechanism of regulating action of FeClP. This aim may be achieved by means of quantum-chemical calculations. In the present work the heats of reactions between FeClP and the model PMMA radicals were determined with density functional theory methods.

\section{Experimental}

Geometry optimizations were carried out with "PRIRODA"[5] package using PBE functional ${ }^{[6]}$ and the $3 z$ basis set. ${ }^{[7]}$ The analytical second derivatives were computed to check whether the optimized structures are the minimum at the potential energy surface. The heats of reactions $\left(\Delta H_{r}\right)$ were estimated as the difference between the total energies of the reaction products and the reagents. The radical $\mathrm{CH}_{3}-$ $\mathrm{CH}_{2}-\mathrm{C}\left(\mathrm{CH}_{3}\right)\left(\mathrm{COOCH}_{3}\right)$ was used as a model of PMMA growing chain. The bulky 3,5-di-tert-butylphenyl substituents in the FeClP molecule were replaced by methyl groups in order to decrease the calculation size.

\section{Results and Discussion}

The molecule of studied metalloporphyrin contains the odd number of electrons. Thus, FeClP is the metalloradical and, on the one hand, OMRP mechanism may be assumed. On the other hand, the reverse ATRP mechanism may be assumed too because of the halogen atom is present in the coordination sphere of iron atom.

The reaction site in the polymeric radicals of methacrylates is delocalized that peculiar to the allyl radicals. It can be represented as the superposition of two resonance structures - carbon- and oxygen-localized radicals:<smiles>CCC(C)C(=O)OC</smiles><smiles>CCC(C)=C([O-])OC</smiles>

Thus, the interaction between PMMA radical and FeClP molecule may proceeds by several ways. All of these possibilities were studied. The recombination reaction of carbon-localized PMMA radical with FeClP leads to formation of product 1 . This reaction is endothermic $\left(\Delta H_{r}=44 \mathrm{~kJ} / \mathrm{mol}\right)$. Figure 1 shows the structure of product 1 (the hydrogen atoms of the porphyrin macrocycle and mesosubstituents are not shown).

The recombination process of oxygen-localized PMMA radical with FeClP is also endothermic $\left(\Delta H_{r}=19 \mathrm{~kJ} / \mathrm{mol}\right)$. 


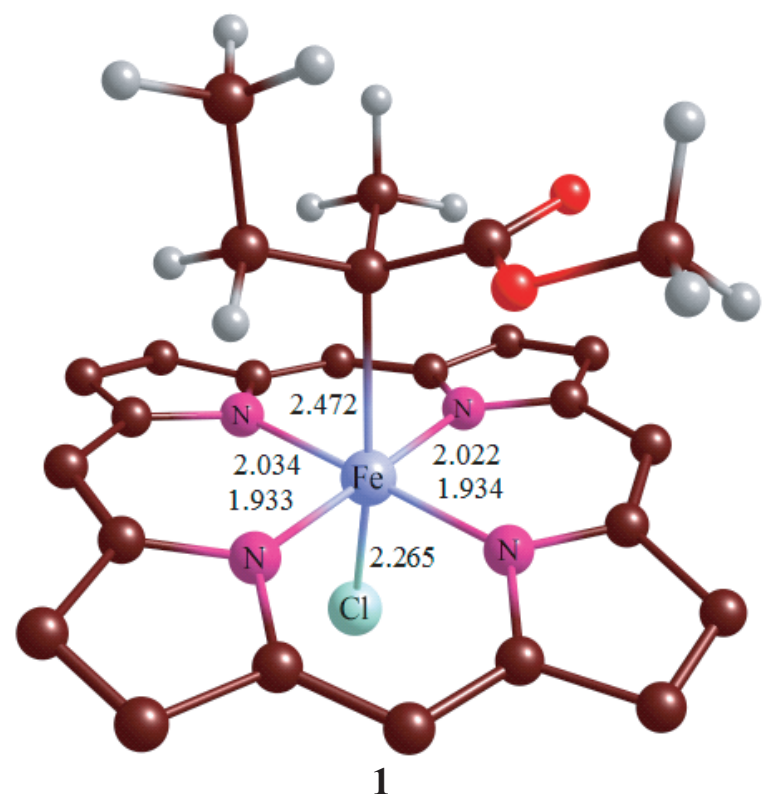

Figure 1. The optimized structure of the product of recombination reaction of carbon-localized PMMA radical and FeClP. Here and further the interatomic distances are expressed in $\AA$.

The product of such reaction (2) is depicted in Figure 2. In the considered recombination reactions FeClP molecule has the low spin multiplicity (1/2), and the products $\mathbf{1}$ and 2 are the singlet particles. The iron porphyrin complex also can exists in the spin states $3 / 2$ and $5 / 2$. The spin states of metalloporphyrins were discussed in literature ${ }^{[8]}$ and it was concluded that the ground state of iron(III)-chloroporphyrins is quartet. The relative energies of the states were calculated in the present work were found to be 0,23 and $37 \mathrm{~kJ} / \mathrm{mol}$, respectively for the states $3 / 2,1 / 2$ and $5 / 2$. The calculated heats of corresponding recombination reactions with participation of $\mathrm{FeClP}$ in the spin state $3 / 2$ are equal to

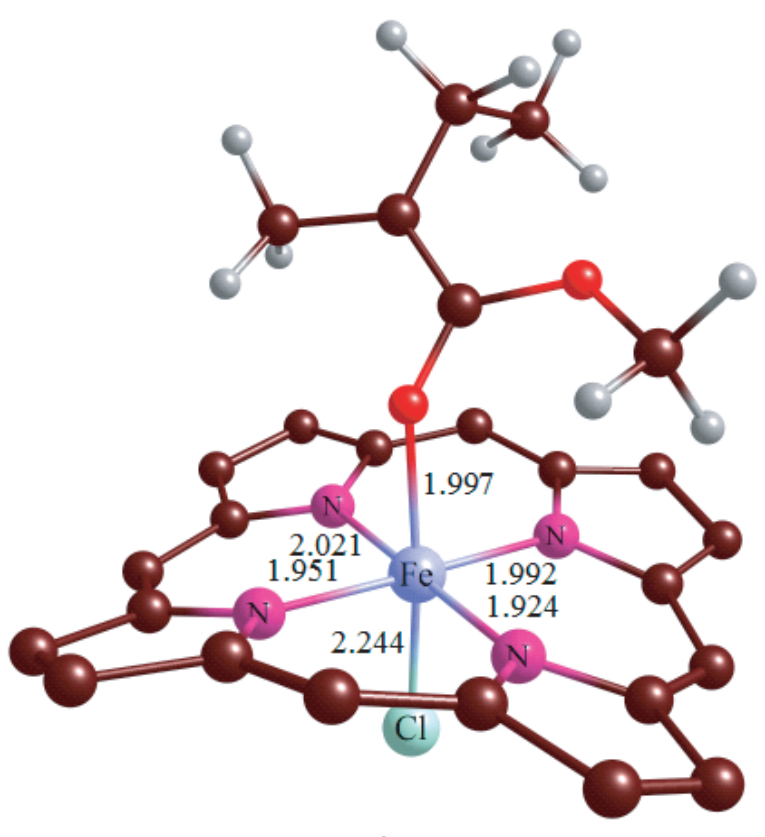

2

Figure 2. The optimized structure of the product of recombination reaction of oxygen-localized PMMA radical and FeCIP.
21 and $4 \mathrm{~kJ} / \mathrm{mol}$, respectively. The products of such reactions (the triplet particles) have the structures similar to $\mathbf{1}$ and $\mathbf{2}$. The $\Delta H_{r}$ values show that the interaction of PMMA radical and FeClP is more favourable via the carbonyl group of the former. The obtained data allow one to conclude that OMRP process cannot be effectively mediated by FeClP itself due to the fact that the equilibrium between the dormant chains and free propagating radicals will be shifted to the active species. However, it may be assumed that the coordination of PMMA growth radical to the iron atom of FeClP may influences the monomer addition step stereochemistry. It was reported ${ }^{[4]}$ that the syndiotacticity of the PMMA synthesized in the presence of FeClP was increased.

Interaction between the oxygen atom of PMMA carbonyl group and chlorine atom of FeClP is impossible due to the negative charges localizing on these atoms. When the carbon-localized PMMA radical interacts with chlorine atom of FeClP $(S=1 / 2)$, the bridged singlet complex 3 (see Figure 3) is easily formed $\left(\Delta H_{r}=1 \mathrm{~kJ} / \mathrm{mol}\right)$. The decomposition of 3 that gives the dormant chain - PMMA-Cl and the singlet particle FeP (ATRP process) is energetically unfavourable $\left(\Delta H_{r}=72 \mathrm{~kJ} / \mathrm{mol}\right)$. Thus, the molecule of $\operatorname{FeClP}(S=1 / 2)$ is not active in the chlorine atom transfer process.

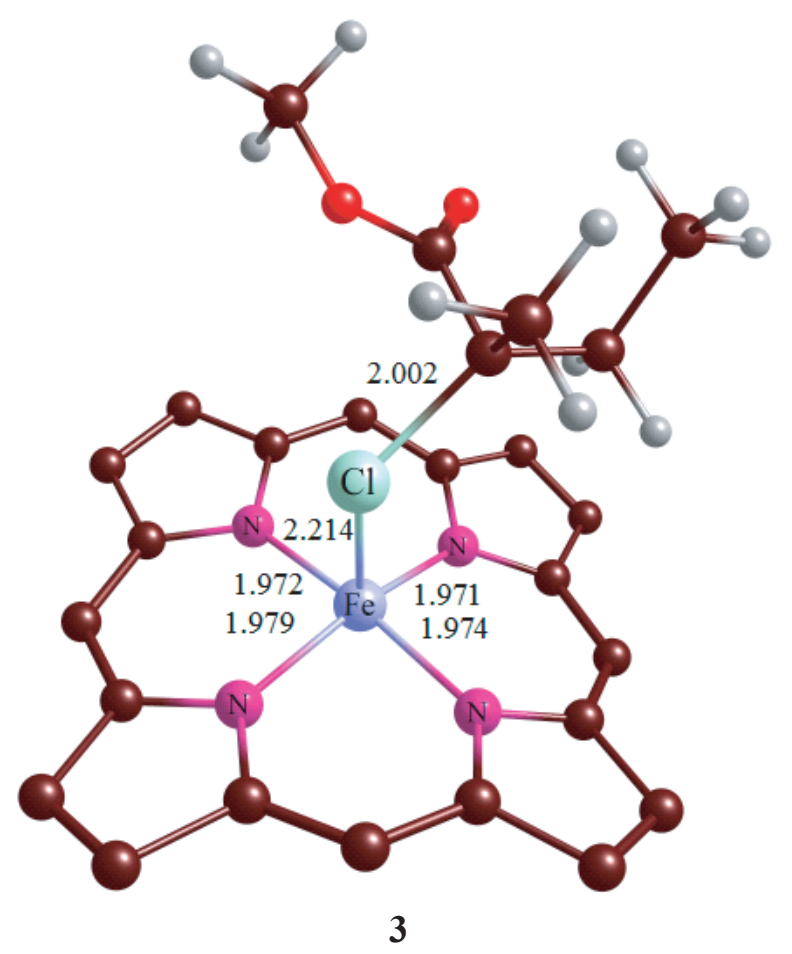

Figure 3. The bridged complex of PMMA radical and FeClP.

The interaction of FeClP in the spin state $3 / 2$ with PMMA radical results in transfer of chlorine atom. Such reaction is exothermic $\left(\Delta H_{r}=-36 \mathrm{~kJ} / \mathrm{mol}\right)$ and leads to formation of PMMA-Cl and the triplet FeP. Thus, the most energetically favourable reaction between the PMMA radical and iron chloroporphyrin is the transfer of chlorine atom (ATRP process).

\section{Conclusions}

The reactions between PMMA radicals and FeClP with the spin multiplicities $1 / 2$ and $3 / 2$ were studied by means 
of quantum chemical calculations. The data obtained in the frames of present investigation evidence that in course of the radical polymerization of MMA in the presence of iron(III) chloroporphyrin the reverse ATRP process is more probable than OMRP. It was revealed that in OMRP process the interaction of iron atom of FeClP and PMMA radical is more favourable via the carbonyl group of the latter. This fact may be the reason of increasing of syndiotacticity of PMMA obtained. ${ }^{[4]}$ The next step towards understanding the mechanism of MMA polymerization process in the presence of $\mathrm{FeClP}$ is the investigation of reactions of PMMA radicals with the triplet particles FeClP(PMMA) and FeP. Also the monomer addition step in the coordination sphere of iron should be considered.

Acknowledgements. This work was supported by RFBR (№ 07-03-12043-ofi) and by President of RF Foundation (SS 2186.2008.3).

\section{References}

1. Poli R. Angew. Chem. Int. Ed. 2006, 45, 5058-5070.

2. Matyjaszewski K., Xia J. Chem. Rev. 2001, 101, 2921-2990.

3. Aida T., Inoue S. Metalloporphyrins as Catalysts for Precision Macromolecular Synthesis, in The Porphyrin Handbook, Vol. 6 (Kadish K.M., Smith K.M., Guilard R., Eds.) New York: Academic Press, 2000, 133-156.

4. Monakov Yu.B., Koifman O.I., Nasretdinova R.N., Islamova R.M., Puzin Yu.I., Ionova I.A. J. Balk. Tribol. Assoc. 2006, 12, 294-302.

5. Laikov D.N., PRIRODA, Electronic Structure Code, Version 6, 2006.

6. Perdew J.P., Burke K., Ernzerhof M. Phys. Rev. Lett. 1996, 77, 3865-3868.

7. Laikov D.N. Dis. kand. khim. nauk (Ph.D. dis.), Moscow, Moscow State University, 2000.

8. Zwaans R., van Lenthe J.H., den Boer D.H.W. J. Mol. Struct. (Theochem) 1996, 367, 15-24.

Received 12.05.2009

Accepted 26.09.2009 